\title{
O COMBATE AO DUMPING SOCIAL NO MERCADO DE CONSUMO ATRAVÉS DO EXERCÍCIO QUALIFICADO DA LIBERDADE DE ESCOLHA DO CONSUMIDOR
}

\author{
Dennis Verbicaro Soares ${ }^{1}$ \\ Gabriela Ohana Rocha Freire ${ }^{2}$
}

Resumo: Este artigo analisa em que medida as informações sobre as práticas desleais de mercado, na modalidade dumping social, podem influenciar no empoderamento decisório do consumidor, sobretudo no exercício responsável de sua liberdade de escolha pelo acesso qualificado à informação, o que lhe permitirá diminuir a relevância mercadológica de fornecedores predatórios. Utilizou-se o método dedutivo de investigação, a partir de pesquisa bibliográfica nacional e estrangeira, concluindo que os novos espaços de interação social podem incentivar o exercício de uma cidadania participativa e a maior conscientização do consumidor.

Palavras-chave: Dumping Social; Informação Adequada; Liberdade de Escolha; Empoderamento Decisório; Consumo Consciente.

\section{COMBATING SOCIAL DUMPING IN THE CONSUMER MARKET THROUGH THE QUALIFIED EXERCISE OF THE CONSUMER FREEDOM OF CHOICE}

\begin{abstract}
This article examines the extent to which information on unfair market practices in the social dumping modality can influence consumer empowerment, particularly in the responsible exercise of their freedom of choice for informed access to information, which will allow them to reduce the relevance of predatory suppliers. The deductive research method was used, based on national and foreign bibliographic research, concluding that the new spaces of social interaction can encourage the exercise of a participatory citizenship and greater consumer awareness.
\end{abstract}

Keywords: Social Dumping; Adequate Information; Freedom of Choice; Decision Empowerment; Conscious Consumption.

\footnotetext{
${ }^{1}$ Doutor em Direito do Consumidor pela Universidade de Salamanca (ES). Mestre em Direito do Consumidor pela Universidade Federal do Pará. Professor da Graduação e dos Programas de Pós-Graduação Stricto Sensu da Universidade Federal do Pará-UFPA e do Centro Universitário do Pará-CESUPA. Procurador do Estado do Pará e Advogado.

${ }^{2}$ Mestranda em Constitucionalismo, Democracia e Direitos Humanos pelo PPGD da Universidade Federal do Pará - UFPA. Bolsista CAPES - Código de Financiamento 001. Pesquisadora do Grupo de Pesquisa "Consumo e Cidadania" - CNPQ. Pós-Graduanda em Direito Público pelo Centro Universitário do Pará - CESUPA. Bacharel em Direito pela UNAMA. Advogada
} 


\section{INTRODUÇÃO}

O fenômeno da globalização trouxe consigo a aproximação das fronteiras territoriais e, dentre outros inúmeros fatores, a intensificação do mercado, que propagou e ainda propaga a fabricação em massa e a maior variedade de produtos e serviços semelhantes a serem ofertados pelos vastos fornecedores. A contemporaneidade transparece pulsar e sobreviver através das veias da economia de mercado.

Nesse sentido, a identidade das marcas (branding) e a imagem dos concorrentes empresariais passa a ser uma das influências diferenciais nas escolhas do consumidor, a cultura do consumo tende a enraizar-se no cidadão capitalista, assim, nos novos tempos a busca incessante pelo lucro sem limites leva o empresário a burlar as leis trabalhistas, a valer-se da mão de obra quase escrava, comercializando produtos com preços bem inferiores aos de mercado, e, aos poucos, nas atitudes desleais, extirpa os concorrentes por meio das práticas de dumping social ${ }^{3}$.

Em contraponto, da mesma forma revolucionária, tecnologicamente o consumidor passou a ter maior acesso às mídias sociais; estas, por sua vez, carregando consigo o poder informacional da coletividade consumerista e de ampla divulgação sobre a satisfação ou insatisfação de um produto ou serviço disposto no mercado pelos mais diversos tipos de fornecedores.

A partir desse panorama, a presente pesquisa se propõe a problematizar em que medida as informações sobre as práticas desleais de mercado, ensejadoras de um verdadeiro dumping social, podem influenciar no exercício responsável da liberdade de escolha do consumidor e no seu consequente empoderamento cívico no mercado de consumo.

Em relação ao aspecto formal, adotou-se o método dedutivo, desenvolvendo-se o conteúdo do artigo através de estudo teórico e pesquisa bibliográfica nacional e estrangeira. Quanto ao aspecto material, destaca-se o contexto da globalização, do mercado e da ordem econômica, em seguida, explanando especificamente acerca do dumping social, da política antidumping brasileira e dos enfrentamentos internos face aos riscos da atividade laboral e à vulnerabilidade informacional do consumidor. Por fim, aborda-se sobre o empoderamento cívico do consumidor pelo exercício responsável de sua liberdade de escolha no mercado,

\footnotetext{
${ }^{3}$ Dumping social pode ser entendido como a prática de concorrência desleal, que consiste na comercialização de bens de consumo a preços inferiores aos de mercado, justo pelo fato de que a obtenção dessas mercadorias foi proveniente através da utilização de mão-de-obra em condições análogas à escravo e com padrões laborais mínimos.
} 
decorrente do acesso à informação qualificada acerca das práticas abusivas praticadas pelos fornecedores de bens e serviços de consumo.

\section{A GLOBALIZAÇÃO E O MERCADO DE CONSUMO}

Em um panorama mundial, a crise do Welfare State, iniciada na década de 70 através dos dois choques do petróleo, trazia à tona a problemática do dirigismo estatal, em que a expansão do Estado o transformava em desordenado, obeso e burocrático, por consequente, em decorrência da democratização política, fulminava-se a debilidade de recursos financeiros para atender as demandas reprimidas que passavam a eclodir naquele momento (SARMENTO, 2004, p. 43). A perda do domínio estatal influenciava, a partir daí, diretamente na economia interna e na fiscalização mercadológica, assim, a visão da abertura dos mercados se portava como uma possibilidade de saída/reestruturação do Estado.

Na visão de Sarmento (2004, p. 44):

Essa crise se acentua em razão da globalização econômica. Esta é o resultado de um processo histórico muito provavelmente irreversível, que se acelerou vertiginosamente nas décadas finais do século XX [...] com a globalização, o que ocorre a milhares de quilômetros, fora dos limites de um Estado, pode influenciar, em tempo real, a vida cotidiana de um cidadão daquele Estado.

nossa):

Nesse contexto, elucida-se os ensinamentos de Tedeschi (2001, p. 160, tradução

Depois da crise do capitalismo mundial nos anos 70, com a súbita paralisação do crescimento econômico que se desfrutou nos anos posteriores à Segunda Guerra Mundial, iniciaram-se algumas mudanças na economia, acompanhadas dos avanços tecnológicos e do triunfo. política da nova direita, que possibilitou uma nova globalização da economia. Isso produziu um impacto no campo jurídico do enfraquecimento do papel do Estado, cuja contrapartida era o fortalecimento do espaço de mercado. Paralelamente a esse processo, percebe-se o desenvolvimento do consumo de forma extraordinária, com tanta força que, no campo do direito privado, rola um novo ator: o consumidor.

Com o fortalecimento do mercado e a acentuação esporádica do fenômeno globalizatório foi possível, como nas palavras de Canclini (2010), uma visão transcendente das culturas locais, estas que preservavam o enraizamento territorial e os espaços de produção e fruição de bens e serviços, e que agora passam a uma racionalidade econômica-consumerista vista pelo paradigma de um processo de montagem multinacional, não mais vislumbrando a internacionalização, e sim um patamar mais amplo, no qual se tornou mais importante a 
velocidade em que se percorre o mundo e o que este tem a oferecer do que as posições geográficas para a satisfação da "necessidade".

Para Bauman (1999, p. 07), “[...] a globalização é o destino irremediável do mundo, um processo irreversível; é também um processo que nos afeta a todos na mesma medida e da mesma maneira". A sociedade global, então, seja em seus processos estruturais, sociais, econômicos, culturais, políticos e ambientais sofreu modificação.

No Brasil, o fenômeno da globalização se intensificava no final dos anos 80 e início dos anos 90. A integração mundial, de fato, rompia agora com as fronteiras geográficas, quer fossem nacionais ou internacionais, gerando uma maior interação funcional a partir da expansão da acessibilidade à internet, um desenfreado desenvolvimento tecnológico, e primordialmente a troca de informações e a diversidade cultural, entretanto, entre os prós ressaltam-se os contras, atinentes às relações de consumo.

O capitalismo, globalização, evolução tecnológica e consumo seguem seus caminhos infimamente atrelados, sendo impossível desvencilhar a ligação entre estes, assim, preleciona Massi (2013, p. 18) "o consumo mantém o sistema capitalista e, para a manutenção do consumo, existe a evolução tecnológica que, por sua vez, promove a intensificação da globalização”.

O lucro mercadológico figura ainda como intrinsecamente ligado à produção dos bens e serviços, deste modo, com a quebra das fronteiras nacionais, o mercado interno se esvaiu ganhando proporções numa perspectiva internacional, causando agora um conflito relacionado ao capital de mercado vs relações de trabalho e desemprego local, nesse interim explana Trierweiler (2009, p. 81 apud MASSI, 2013, p. 22):

Essa tendência empresarial, de ultrapassar as fronteiras para instalação da produção, tem como escopo a busca de novas condições sociais, de normas trabalhistas diversas que se apresentam em cada Estado. Afinal, no meio da turbulenta crise econômica que vem se espalhando pelo mundo, nada mais coerente do que se buscar formas de atenuar custos que são diretamente ligados ao preço final do produto - os custos da mão de obra. Migrando-se para países com uma legislação trabalhista mais branda, as grandes multinacionais conseguem reduzir seus custos com a mão de obra empregada, tornando seus produtos mais competitivos no comércio exterior.

Para Silva (2014, p. 185) “o grande problema gerado por essa nova gestão econômica é que os valores de mercado deixaram de ser restritos aos aspectos da economia de compra e venda de bens materiais; eles passaram a governar, de forma crescente e imperialista, nossa vida como um todo [...]", assim, o respeito à Dignidade da Pessoa Humana e a valorização dos princípios éticos e morais da sociedade foram sendo deixados em segundo plano. 
Em linhas gerais, a busca incessante do mercado global é manter aceso o capitalismo voraz, que devora a sociedade consumerista por meio dos desejos despertados pelas "falsas" ambições de necessidade de bens e serviços materiais, implantando uma ditadura econômica que se volta mais para o lucro dos fornecedores do que para o bem-estar social da coletividade; assim, em tempos da hipermodernidade, vivencia-se uma espécie de felicidade paradoxal ${ }^{4}$ consumerista, sendo esta a peça fundamental em prol da movimentação da máquina capitalista que nunca para.

\subsection{A ordem econômica: entre a livre concorrência e as práticas desleais de mercado}

O capitalismo pós globalização, no cenário nacional e internacional, frente ao encurtamento e imediatismo das transações comerciais e financeiras, tem ocasionado um mercado e empresários-fornecedores cada vez mais competitivos e concorrentes entre si, em razão de promover um maior número de mercantilização dos produtos e serviços e difundir a marca para o máximo possível de consumidores.

Entretanto, a busca pela enorme fatia mercadológica exige das empresas o respeito à livre concorrência e a vedação às práticas desleais de mercado que extirpem outras empresas do comércio. Deste modo, o sistema estrutura-se para que opere seu funcionamento conforme os moldes da ordem econômica compatibilizada com a justiça social, a iniciativa privada e a dignidade da pessoa humana.

No Brasil, no que tange ao direito de concorrência, desenvolveu-se a partir de $1934^{5}$ a normatização da intervenção estatal em rumo da economia de mercado. Atualmente, a ordem econômica e a livre iniciativa estão previstas no bojo da Constituição Federal de 1988, referindo-se não apenas a defesa de uma economia popular e local, mas sim fortalecida na ideologia de uma ordem de mercado transnacional e com a devida noção de defesa do consumidor.

Para Schneider (2016, p. 248):

Se a concorrência não é um fim em si mesma, mas um instrumento que, no caso brasileiro, permite a consecução dos objetivos fundamentais da República e de ordem econômica que tem por fim assegurar a todos existência

\footnotetext{
${ }^{4}$ Denominações de "hipermodernidade" e "felicidade paradoxal" são advindas do autor Gilles Lipovestky, nas respectivas obras intituladas de "Os tempos hipermodernos" (2004) e "A felicidade paradoxal: ensaios sobre a sociedade de hiperconsumo" (2007).

${ }^{5}$ A partir da Constituição Federal brasileira de 1934 todas as demais constituições posteriores passaram a conter capítulo acerca da Ordem Econômica.
} 
digna, conforme os ditames de justiça social, há a necessidade de se verificar os diversos fins que ela visa implementar, inter alia a defesa do consumidor.

A livre iniciativa, apreciada como um dos fundamentos da República Federativa do Brasil, vide art. $1^{\circ}, \mathrm{IV}$ da $\mathrm{CF} / 88$, seria a liberdade de escolha do empresário para com o exercício de suas atividades econômicas, sem a presença do intervencionismo estatal, desde que respeitados os comandos legais, da justiça e o bem-estar social.

De todo modo, muito embora a livre iniciativa seja o norte do desenvolvimento econômico do País, tal princípio encontra algumas delimitações, estabelecidas no bojo do art. 170 da CF/88, tais como a valorização do trabalho humano, busca do pleno emprego, e dentre outros a defesa do consumidor, almejando compatibilizar e harmonizar a ordem econômica com as regras constitucionais e a soberania nacional.

Nos moldes da liberdade, a livre concorrência deve permitir a pluralidade de fornecedores/produtores de um mesmo produto ou serviço, expandindo as opções mercadológicas e garantindo ao consumidor possibilidades de escolhas que priorizem, dentre outros atributos, qualidade e preço, nestes termos, elucida Schneider (2016, p. 258):

É certo, assim, que a ausência de concorrência, ou sua limitação, é passível de reconhecimento e terá efeitos sobre o bem-estar do consumidor, podendo comprometê-lo. Não por acaso, considera-se que o consumidor é o destinatário das normas concorrenciais, sendo seu bem-estar uma espécie de Leitmotiv perseguido pelas autoridades antitrustes. Contudo, essa perspectiva deve ser considerada cum grano salis, visto que uma interpretação do antitruste baseada tão somente no interesse do consumidor poderia até mesmo prejudicá-lo. Um exemplo recorrente disso diz respeito à pratica de preços predatórios, prevista no art. 36, XV da Lei 12.529/2011, uma prática anticoncorrencial que, inicialmente, poderia beneficiar o consumidor, mas que a longo prazo, o prejudica em aspectos multifatoriais [...].

Contudo, a caracterização da concorrência desleal não é algo simples, posto que para uma melhor compreensão sobre a idoneidade ou inidoneidade das práticas de mercado é necessário, conforme Almeida (2004, p. 120), o reconhecimento de três requisitos, quais sejam, o mesmo tipo de produto ou serviço a ser oferecido por duas empresas; o tempo, compreendendo que a prática desleal entre dois fornecedores deve acontecer no mesmo limite temporal; e por fim, a identidade territorial.

Em síntese, há necessidade da manutenção da ordem econômica, pois a prática da concorrência desleal configura ato ilícito empresarial que atenta contra a livre iniciativa e a livre concorrência, ocasionando o desequilíbrio da ordem econômica e a necessidade de proteção direta ao consumidor, visto que a liberdade de escolha da parte mais vulnerável da 
relação passa a ser tolhida arbitrariamente pelo forma abusiva de alguns concorrentes desleais visarem uma posição predominante no mercado em detrimento do seu lucro e em prejuízo dos demais concorrentes leais.

\subsection{O cidadão capitalista e a cultura do consumo}

Cláudia Lima Marques (2014, p.150) explana que:

Desde o fim do século XX e início do século XXI, que é inegável é a importância do consumo a, de certa forma, definir a nova vida privada, uma sociedade não mais de "produtores", mas de "consumidores": a sociedade de consumidores, que o próprio Bauman critica como um "mundo líquidomoderno dos consumidores", capaz de transformar tudo, mesmo seres humanos, em mercadoria: consumindo a própria vida (consumer life).

Nesse aspecto, a economia de mercado, a qual alicerça o capitalismo, jamais foi tão capaz de direcionar a escolha do cidadão-consumidor a consumir "necessidades" que compõem as suas riquezas de bens materiais. Para Silva (2014, p. 178), "pela lógica da sociedade consumista, se mais e mais pessoas estão tendo melhores condições financeiras, era de se esperar que o número de pessoas felizes crescesse com o mesmo vigor".

Eis o motivo pelo qual Verbicaro (2017, p. 53) elucida:

Na verdade, em uma sociedade globalizada, todos acabam se tornando vítimas de inúmeras espécies de coação econômica. Muitas vezes, as pessoas são levadas a realizar determinadas ações, aceitar determinados produtos e serviços sob condições claramente desvantajosas. E se o fazem é por que são ignorantes, por que não sabem exercer sua cidadania a ponto de reivindicar a mudança daquela realidade? Não. É simplesmente porque, muitas vezes, não há essa alternativa, pois, o cidadão acaba sendo forçado a ceder às normas contratuais injustas, porque o desequilíbrio econômico, técnico e jurídico assim lhe impõe, fazendo com que a manifestação de vontade acabe sendo comprometida, não havendo, portanto, que se falar em vontade livre.

É inegável que a vontade livre do cidadão capitalista é hoje extremamente direcionada à cultura do consumo, em que se associa a ideia de qualidade de vida ao consumo para alcance da felicidade, sendo então o Ser feliz aquele que se vale do seu poder aquisitivo para comprar a sensação de alegria intensa que se esvai e se transforma em obsoleta em um piscar de olhos, no próprio ato de compra, da frequentemente e, na maioria das vezes, da falsa necessidade produzida pela indústria cultural.

O grande embate da questão é que o indivíduo, ao almejar apenas suas satisfações pessoais em prol de saciar a necessidade de compra, acaba voltando à estaca zero, retornando à sociedade indolente, na qual não se via o consumo como a primazia do bem-estar de uma 
coletividade, visando uma proteção da metaindividualidade, mas sim a partir de um ponto de vista meramente egoísta e individual.

Nesse ínterim, não há como discordar de Lipovetsky (2007, p. 192):

Mediador da "verdadeira vida", o consumo é igualmente revestido do que permite escapar o desprezo social e à imagem negativa de si. A obsessão do consumo, observável, em nossos dias, até nas populações marginalizadas, não indica apenas o poder sem precedentes da mercantilização dos modos de vida, mas também a nova intensidade das frustrações em relação aos padrões de vida dominantes [...] importa cada vez mais, para o indivíduo, não ser inferiorizado, atingido em sua dignidade.

Canclini (2010, p.42) entende que a visão neoliberalista da globalização proporciona a desigualdade entre direitos, e por consequente restringe o ato decisório sobre a produção, distribuição e utilização dos bens e serviços ofertados no mercado daquele cidadão com menores condições de consumir. A mercadoria então passa a cada momento a insurgem como novidades modernas, para uns como meros objetos de consumo e para outros como espetáculos.

Assiste razão as palavras de Bauman (2008, p. 88-89):

O pressuposto tácito subjacente a esse raciocínio é, uma vez mais, a fórmula "sem consumidor não há mercadoria". A comodificação precede o consumo e controla o acesso ao mundo dos consumidores. É preciso se tornar uma mercadoria para ter chance razoável de exercer os direitos e cumprir os deveres de um consumidor

Eis que se indaga então, vivemos para consumir ou consumimos para viver? ${ }^{6}$

O mercado de consumo bebe na fonte do sistema econômico capitalista, que para manter seus motores sempre aquecidos e autossustentáveis, baseado no lucro sem limites, fecha os olhos para os atos abusivos, nocivos e extremamente irresponsáveis dos fornecedores para com os consumidores (SILVA, 2014, p. 35), implicando no consumo inconsciente, irracional e cada vez menos disposto a atender as reais necessidades, se demonstrando mais afeto a manipular o consumidor-cidadão para supostamente enquadrá-lo na sociedade.

\section{O DUMPING SOCIAL}

Dumping é a expressão denominada para configurar as práticas desleais de concorrência mercantil em nível internacional (ALVES, 2017, p. 41). Tais atos são realizados com intuito único e exclusivamente direcionado à obtenção de vantagem na comercialização de produtos, extirpando aos poucos os demais concorrentes e ganhando novos mercados. Ainda,

\footnotetext{
${ }^{6}$ Ideologia exposta por Bauman (2008).
} 
acerca do dumping é possível compreender, pelos ensinamentos de Massi (2013, p. 40), que tal prática se caracteriza:

[...] como uma forma de concorrência desleal de caráter internacional, que consiste na venda de produtos pelo país exportador com preços abaixo do valor normal, não necessariamente abaixo do preço de custo, praticados no mercado interno do país exportador, podendo causar ou ameaçar causar danos às empresas estabelecidas no país importador ou prejudicar o estabelecimento de novas indústrias no ramo neste país.

A lei concorrencial e as limitações às práticas de mercado foram primeiramente desenvolvidas no Canadá, e por consequente, após 1889, nos Estados Unidos da América (EUA), face ao poder mercadológico das organizações empresariais, denominadas de trusts, passou a vigorar um arsenal legislativo que visava, de modo exclusivo, apenas a existência de economia de mercado, sem inicialmente se preocupar com o direito do consumidor (SCHNEIDER, 2016).

No ordenamento jurídico brasileiro, a recepção da prática desleal de mercado, denominada de dumping, foi adotada por meio do Decreto ${ }^{\circ}$. 1.602 , de 1995, que regulamentou a Lei $\mathrm{n}^{\circ}$. 9.019/95, preceituando em seu art. $4^{\circ}$ como: “considera-se prática de dumping a introdução de um bem no mercado doméstico, inclusive sob as modalidades de drawback, a preço de exportação inferior ao valor normal".

O dumping poderá ser praticado em diversas modalidades, todavia, todas as vezes que a mercantilização a preços inferiores seja de bens que foram obtidos mediante a utilização reiterada de mão-de-obra inadequada e em desacordo com os mínimos padrões laborais permitidos em lei, estará evidente a caracterização específica do dumping social. Nesse sentido, Alves (2017, p. 41) explicita:

Observe-se, contudo, que para que o dumping seja caracterizado como "social
trabalhista", é indispensável que a vantagem econômica e financeira
(traduzida na redução dos custos, no aumento do lucro e no alijamento da
concorrência) seja obtida mediante o desrespeito aos direitos sociais. Não são
poucos os exemplos de inobservância e violação de direitos trabalhistas que,
não raras vezes, são verificados no cotidiano das empresas, como a ausência
de reconhecimento de vínculo de emprego, a supressão de pagamento de
parcelas de direitos como horas extras, adicionais (que repercutem na esfera
social ante a falta de incidência de encargos), além da precarização das
condições de trabalho de forma geral (ALVES, 2017, p. 41).

Nesse viés, tal prática de dumping social, como mera forma de majoração lucrativa e de elevar a vantagem empresarial sobre a concorrência, infringe diretamente a legislação constitucional, bem como a infraconstitucional, seja a Lei 12.259/2011, que dispõe sobre a 
prevenção e repressão às infrações decorrentes das práticas desleais, assim como a legislação trabalhista e o microssistema de proteção do consumidor, causando graves impactos em toda a produção mercadológica, ao passo que desestrutura a ordem econômica, além de ocasionar sérios prejuízos para a justiça social e para a coletividade.

A caracterização do dumping exige imprescindivelmente a reunião de alguns elementos, quais sejam nas palavras de Tostes $(2014$, p. 61) “ (i) a comprovação do dano material ou a ameaça de dano material à indústria doméstica; (ii) a indústria doméstica deve ser já estabelecida ou o dano deve afetar/retardar a implantação de indústria; (iii) deve haver um nexo de causalidade comprovado entre o dano e a prática do dumping”.

Ressalte-se que, em termos de matéria concorrencial e de dumping comercial, o Conselho Administrativo de Defesa Econômica (CADE) é a autarquia responsável por disciplinar o tema no Brasil, por meio de três controles, quais sejam, o repressivo, preventivo e educacional; entretanto, em matéria de dumping social inexiste legislação específica e órgão que combata diretamente este tipo de prática, subsidiando-se para efeitos fiscalizatórios nas Convenções e Resoluções da Organização Internacional do Trabalho (OIT), Organização Mundial do Comércio (OMC) e Ministérios Públicos do Trabalho (MPT’s).

\subsection{A Política antidumping brasileira, o enfretamento interno frente aos riscos da atividade} laboral e o desrespeito à vulnerabilidade informacional do consumidor

Em uma sociedade exacerbadamente capitalista como a atual, a busca pela compatibilização da ordem econômica e a limitação das práticas de mercado correlacionadas com o respeito à justiça social e à Dignidade da Pessoa Humana, tem enfrentado questões sensíveis relacionadas ao valor social do trabalho.

Nesse contexto, torna-se mais fácil a compreensão do assunto através do que expõe Silva (2014, p. 30):

[...] As grandes corporações passaram a delegar a tarefa "menos nobre" de produzir simples mercadorias em países de Terceiro Mundo, onde a mão de obra é muito barata, as leis trabalhistas são débeis e as isenções fiscais, concedidas por anos ou até décadas. Tudo o que essas fábricas terceirizadas precisam fazer é dar conta das encomendas a tempo e no valor acordado que, pelo exposto, costuma ser o mínimo possível [...] Enquanto os trabalhadores distantes, desconhecidos e miseráveis fabricam os produtos, as matrizes poderosas e libertas dos embargos produtivos estão prontas para investir bilhões de dólares no que realmente importa: dar alma e significado extraordinários aos objetos produzidos em um "inferno trabalhista qualquer". 
Para isso, elas só precisam "batizá-los" com suas marcas poderosas e desejadas.

Um plausível justificativa para essa submissão dos trabalhadores às condições precárias do meio ambiente de trabalho, por vezes, em palavras mais claras, condições análogas à escravo, deve-se ao temor do desemprego. "Vive-se mal para trabalhar e não mais se trabalha para bem viver, esqueceu-se que aquele que produz, somente o faz de forma exímia para construir sua identidade social e inserir-se na sociedade como ser humano" (TOSTES, 2014, p. 25).

Assim, é errado reconhecer e permitir no ordenamento jurídico brasileiro, face a existência de um diálogo entre o Sistema Brasileiro de Defesa da Concorrência (SBDC) e Sistema Nacional de Defesa do Consumidor (SNDC), que as práticas de mercado visando apenas o lucro sejam prevalecentes frente à incumbência permanente do Estado para com a realização de direitos fundamentais de eficácia irradiante, como os direitos trabalhistas.

Seria simples e sedutora que a transnacionalização globalizante implicasse em ausência de regulações trabalhistas, redução de custos de produção e fragilidade de legislação concorrencial, apenas em prol de condições favoráveis para o fornecedor e o domínio econômico, mas a realidade é outra, pois é preciso, para concorrer lealmente no mercado, reconhecer as vulnerabilidades da relação empregatícia e proporcionar os padrões laborais mínimos.

Nesse diapasão, não se torna muito improvável encontrar empresas no âmbito comercial nacional e internacional que estejam em desconformidade com a política antidumping, prevista na Lei 12.529/2011. Com a globalização e os avanços tecnológicos, não se pode esquecer que as mídias sociais também foram encurtadas, e do mesmo modo que proporcionaram um mercado mais atrativo, também são responsáveis pela propagação de notícias que desabonem as condutas de dumping social.

Diversas marcas multinacionais como a Farm (FARM, 2017), Brookfield (BROOKFIELD, 2015), Santander (TRT, 2014), dentre outras, foram e continuam sendo difundidas nos ambientes virtuais como empresas praticantes de concorrência desleal social e predatória, quando devidamente apuradas suas infrações a aplicadas as penalidades cabíveis. $\mathrm{Na}$ era digital, este fator para o consumidor possibilita o acesso à informação sobre os maus fornecedores, conscientizando e permitindo, a partir de tal fato, uma ampla liberdade de escolha e o respeito ao direcionamento por compras que primem pelo valor justo.

Acerca do acesso informacional, Marques (2014, p. 162) preceitua: 
A decisão de "informar" é a decisão de (dar) forma e passar de seu âmbito de domínio algo imaterial para o outro, a informação. Também, no aspecto positivo, o comunicado/informado é uma forma de responsabilidade (Verantwortung), a informação leva à imputação (Zurechnung) de um agente da sociedade pela confiança criada, a informação/omissão leva à imputação de responsabilidade.

O desrespeito à vulnerabilidade informacional é então entrave entre a livre iniciativa e o dumping, pelo fato de que a informação é um instrumento essencial para a garantia de direitos e cumprimento de deveres do consumidor, cuja ausência pode ocasionar sérios riscos à sociedade de consumo.

O acesso à informação clara e adequada encaminha para a conscientização individual de escolhas e de igualdade nas contratações, que em conformidade com o art. $6^{\circ}$, II do CDC, permite ao consumidor, indiretamente, que este venha a ser o filtro da sociedade mercadológica, em outros termos, o consumidor consciente individual, por meio de suas compras conscientes, é capaz de extirpar aos poucos da economia os fornecedores desleais, assim, exercendo sua cidadania em prol da coletividade.

Portanto, o ato da compra pelo consumidor não de ser feito de maneira alienada, guiado apenas pela compulsão da falsa necessidade idealizada pelo capitalismo, deve sim avaliar conscientemente a identidade da marca (branding) e a valorização que esta imprime diante do respeito aos trabalhadores que constroem as suas mercadorias e sua imagem de mercado, afinal, não se pode permitir que concorrentes desleais se alimentem do "gosto amargo do trabalho quase escravo de pessoas que vivem sem nome e são descartáveis nessa engrenagem de fantasia conceitual" (SILVA, 2014, p. 31).

\section{O EMPODERAMENTO CÍVICO CONSUMERISTA DECORRENTE DOS NOVOS ESPAÇOS DE INTERAÇÕES SOCIAIS}

Diante de um sistema econômico que se baseia na busca incessante pelo lucro para manter suas veias pulsando e sobre a divulgação de empresas que praticam dumping social no mercado, conforme já demonstrado, o consumidor torna-se um Ser digno e capaz de fazer as exclusões e inclusões acerca das suas escolhas sobre os fornecedores leais e desleais concorrencialmente, entretanto, esse fator do livre arbítrio decorre substancialmente do poder informacional das mídias sociais e do empoderamento de uma decisão cidadã consciente.

\subsection{O poder da influência midiática informacional}

Nas palavras de Verbicaro (2017, p. 123): 
Num mundo globalmente capitalizado, o indivíduo se tornou refém de seus impulsos materialistas, que sobrevalorizados pelos meios de publicidade e convencimento em massa, são vendidos como verdadeiras necessidades de consumo, supostamente fundamentais para o bem estar físico e, sobretudo, psíquico.

De fato, não é de hoje que as relações de consumo são cada vez mais influenciadas pelo marketing, compreendido através da publicidade e propaganda. Com efeito, as inovações tecnológicas têm afetado incisivamente o comportamento do consumidor; aquele que antes pouco tinha acesso aos conteúdos informacionais, agora, por meio das mídias sociais, busca inflamar suas possibilidades interativas multidirecionais na busca incessante de se manter conectado/informado.

As mídias sociais relacionam-se à ideia de comunidade, na qual a participação coletiva dos cidadãos, para manter a sociabilidade e as relações de apoio, alicerça o espaço cibernético, o então ambiente Web 2.0. O nível de participação dos cidadãos, o interesse coletivo e o poder de massa possibilitado pelas redes midiáticas agrega valor democrático às comunidades, por sua vez impondo, em fluxos, novos padrões comportamentais.

Em decorrência de tais fluxos informacionais e do alargamento das influências midiáticas sobre a identidade das marcas, Solomon (2002, p. 518) elucida:

Para as empresas, os fluxos são particularmente importantes porque são componentes acionáveis de qualquer sistema de rede social com relação ao compartilhamento de informações, à distribuição de conteúdo promocional e às fontes de influência social. A extensão dessa influência social (em que ponto as atitudes ou o comportamento de uma pessoa mudam em decorrência de tentativas alheias) varia dependendo do poder ou da atratividade dos outros nós.

Nesse sentido, a comunicação boca a boca ${ }^{7}$ e a comunicação por mídias sociais são capazes de reduzir a credibilidade da publicidade e da empresa quando frente à insatisfação do consumidor sobre determinado fornecedor. Deste modo, o poder persuasivo e influenciador expressivo de valores negativos em prol de um mercado mais equilibrado tem impacto diretamente proporcional.

De acordo com um estudo realizado pelo Escritório de Defesa do Consumidor da Casa Branca (SOLOMON, 2002, p. 505), demonstrou-se que 90\% dos clientes insatisfeitos e desapontados com as marcas deixaram de lado as compras em fornecedores desleais, fator que

\footnotetext{
${ }^{7}$ Para Solomon (2002, p. 502), a comunicação boca a boca caracteriza-se por ser "a informação sobre produtos transmitidas de indivíduos para indivíduos. [...] E diferente da propaganda, o boca a boca com frequência é acompanhado da pressão social para que nos conformemos com essas recomendações."
} 
sem sombra de dúvidas demonstra que a escolha do consumo, por meio da informação adequada, é o que dimensiona a extensão de quem deve permanecer na comercialização, até porque empresas bem cotadas na satisfação consumerista se beneficiam em termos de vantagem competitiva.

\subsection{O exercício da cidadania consciente decorrente do acesso à informação adequada}

Nos dias atuais, sem sombra de dúvidas a conscientização do consumidor é peça fundamental para o equilíbrio concorrencial face as práticas desleais de mercado por alguns fornecedores. E por óbvio, a sociedade capitalista muitas vezes poderá considerar e pensar de modo individual sobre o fato das premissas " não sou endividado", "eu consigo pagar", "posso bancar as minhas necessidades", entretanto, como preleciona Silva $(2014$, p. 36) "a questão não é simplesmente poder gastar, e sim consumir exercendo a responsabilidade de viver em sociedade e pensar no mundo que deixaremos para as próximas gerações".

Em seguimento à linha de raciocínio, assiste razão a Verbicaro (2017, p. 129):

Compete à sociedade civil e à opinião pública o papel de inquisidoras das mazelas do sistema democrático, como garantia do seu próprio aperfeiçoamento, porquanto serão realizadas, com a participação cívica, as mudanças que o próprio sistema necessita para desenvolver melhor suas metas. Reside aí também a importância da desobediência civil. É uma espécie de alarme de segurança que deve disparar quando algo na democracia está errado ou funciona mal.

O consumo irracional distorce os reais prazeres e a livre necessidade de escolhas, influindo diretamente na consciência, a qual "é a estrutura essencial e determinante da nossa índole" (SILVA, 2014, p.189). Deste modo, o fato de o Ser Humano ser eivado de ética e moralidade é justamente proveniente da voz consciente que o empodera, não permite a existência solitária e nem o isolamento afetivo do mesmo, conduzindo-o a não pensar egoisticamente, mas sim pensar no bem comum da sociedade (SILVA, 2014, p. 189).

Ser um consumidor consciente é preocupar-se em ser um cidadão mais ativo em prol do exercício democrático de suas escolhas. Nesse sentido, a informação, direito fundamental da Pessoa Humana, infere diretamente sobre o livre arbítrio das escolhas do consumidor; e em se tratando de poder seletivo em relação ao mercado, pode e deve a parte mais vulnerável da relação jurídica ser uma das engrenagens que impulsiona o fornecedor a mudar suas atitudes quanto à concorrência desleal social, que usa da dignidade do trabalhador para obter lucros. 


\section{CONCLUSÃO}

O Dumping Social caracteriza-se por ser a execução de um conjunto de práticas desleais de mercado, na qual a comercialização de produtos é realizada com valor abaixo daquele praticado pela concorrência. Para essa finalidade, o fornecedor se utiliza da precarização de mão de obra, de matéria-prima de baixa qualidade, o que influi diretamente na diminuição da durabilidade dos bens de consumo, não investe no aprimoramento tecnológico e na gestão de qualidade de seu processo produtivo, ignora a solução extrajudicial dos conflitos de consumo e com isso consegue oferecer um processo significativamente abaixo da média de mercado, inviabilizando a livre concorrência e a manutenção dos fornecedores responsáveis.

Tal ato desequilibra a ordem econômica, a qual, em conformidade com o art. 170 da $\mathrm{CF} / 88$, deve ser mantida no ordenamento jurídico brasileiro. Inegável se torna, ainda, a latente afronta à Dignidade da Pessoa Humana, quer seja do trabalhador explorado, condicionado a condições degradantes e a pagamento irrisório salarial, quer seja sobre a escolha do consumidor, haja vista que há manobras que ludibriam o valor de compra em detrimento apenas de lucro do fornecedor, tornando o "preço" um dos atrativos que mais vulnera o consumidor a longo prazo.

No cenário comercial, ainda que se reconheça a prática desleal para com a justiça social e sejam veiculadas informações sobre as empresas que ferem a livre concorrência, a ausência de órgão fiscalizador específico dificulta a maior divulgação sobre os fornecedores predatórios, ensejando a necessidade de criação de um órgão específico que realize um controle interno e externo mais efetivo; um controle que cative ao consumidor por meio do acesso às informações e não que preze apenas pelo mercado.

Nesse sentido, a informação, direito fundamental do cidadão-consumidor, transformase então na peça fundamental para o empoderamento consumerista, ganhando proporções amplas quando veiculadas por plataformas virtuais de reclamação, espaços de compartilhamentos de experiências já presentes na grande maioria dos sites de comércio eletrônico, como também pelas novas redes de interações, quais sejam, websites, blogs, imprensa digital, Facebook, Whatsapp, Twiter, Instagram, dentre outros.

No momento atual, principalmente em decorrência da globalização e da massificação das práticas abusivas, o dumping social agrava a vulnerabilidade do consumidor, não apenas porque frustra suas expectativas quanto à adequação, durabilidade e segurança dos bens de consumo, como também gera uma concorrência desleal com os fornecedores responsáveis e 
comprometidos com seus deveres éticos para com a coletividade de consumidores, daí porque merece ser combatida.

Justamente, nesse sentido, que em tempos de encurtamento de fronteiras mercadológicas e de expansão das mídias sociais, bem como de perda de credibilidade do Estado como mediador responsável no mercado de consumo, urge provocar o consumidor a exercer essa participação qualificada no mercado de consumo pela busca consciente de informações sobre a reputação e experiência do fornecedor.

Nesse sentido, o maior interesse e acesso à informação sobre o comportamento predatório dos fornecedores, bem como pelo melhor nível de conscientização e compartilhamento de experiências de consumo, sobretudo em redes sociais e plataformas virtuais, torna-se possível combater o Dumping Social, alijando empresas e fornecedores que agem na infralegalidade pelo simples exercício consciente da liberdade de escolha pelo consumidor.

Isso porque num ambiente excessivamente competitivo como é o mercado de consumo, uma experiência ruim, ou um testemunho negativo acerca da qualidade, segurança ou mau atendimento do consumidor, terá o condão de influir exponencialmente na decisão de futuros consumidores, tornando irrelevante, ou mesmo excluindo o capitalista desleal.

\section{REFERÊNCIAS BIBLIOGRÁFICAS}

ALMEIDA, Marcus E. Michelli. Abuso de direito e a concorrência desleal. São Paulo: Quartier Latin, 2004.

ALVES, Paulo Henrique Molina. A teoria do Dumping Social trabalhista aplicada na ordem jurídica brasileira: Responsabilização empresarial pelos danos sociais praticados. 2017. 112 f. Projeto de Dissertação de Mestrado (Mestrado em Direito Empresarial e Cidadania). Centro Universitário Curitiba - UNICURITIBA, Curitiba, 2017.

BAUMAN, Zygmunt. Vida para Consumo: transformando pessoas em mercadorias. Tradução Carlos Alberto Medeiros. Rio de Janeiro: Jorge Zahar, 2008.

BRASIL. Constituição da República Federativa do Brasil de 1988. Diário Oficial [da] União, Brasília, DF, 05 de outubro de 1988. Disponível em: <http://www.planalto.gov.br/ccivil_03/constituicao/constituicaocompilado.htm>. Acesso em: 03 jul. 2018.

. Lei ${ }^{\circ} 8.078$, de 11 de setembro de 1990. Dispõe sobre a proteção do consumidor e dá outras providências. Diário Oficial [da] União, Brasília, DF, 12 set. 1990. Disponível em: <http://www.planalto.gov.br/ccivil_03/leis/L8078.htm>. Acesso em: 03 jul. 2018. 
BROOKFIELD é condenada a pagar R\$ 2 milhões por prática de dumping social. Época Negócios. jul. 2015. Disponível em: <https://epocanegocios.globo.com/Informacao/Dilemas/noticia/2015/07/brookfield-e-

condenada-pagar-r-2-milhoes-por-pratica-de-dumping-social.html>. Acesso em 20 jul. 2018.

CANCLINI, Néstor García. Consumidores do Século XXI. $8^{\text {a }}$ Edição. Rio de Janeiro: UFRJ, 2008.

FARM é condenada em R\$ 500 mil por dumping social. Migalhas. jul. 2017. Disponível em: <http://www.migalhas.com.br/Quentes/17,MI262199,71043-

Farm+e+condenada+em+R+500+mil+por+dumping+social>. Acesso em 20 jul. 2018.

GOLDENSTEIN, A.I. B.A; DUTRA, L.Z. Impactos do Dumping Social na ordem econômica e ao valor social do trabalho. ANIMA: Revista Eletrônica do Curso de Direito das Faculdades OPET. Curitiba PR - Brasil. Ano VIII, n $\square$. 15, jul/dez 2016. ISSN 2175-7119.

LIPOVESTKY, Gilles. Os tempos hipermodernos. São Paulo: Barcarolla, 2004.

A felicidade paradoxal: Ensaios sobre a sociedade de hiperconsumo. São Paulo: Companhia das Letras, 2007.

MASSI, Juliana Machado. A crise econômica e o dumping social: a necessidade de mudança de paradigmas entre o comércio e as relações de trabalho para se atingir o verdadeiro interesse social. 2013. 113 f. Dissertação (Mestrado em Direito). Pontifícia Universidade Católica do Paraná, Curitiba, 2013.

MARQUES, Cláudia Lima. O novo direito privado e a proteção dos vulneráveis. 2 ed., rev. atual. e ampl. São Paulo: Revista dos Tribunais, 2014.

MENDES, Gilmar Ferreira; BRANCO, Paulo Gustavo Gonet. Curso de Direito Constitucional. 1 ed. rev. e atual. São Paulo: Saraiva, 2015. (Série IDP).

SARMENTO, Daniel. Direitos fundamentais e relações privadas. Rio de Janeiro: Lumens Juris, 2004.

SANTOS, Fabíola Meira de Almeida. Informação como instrumento para amenizar os riscos na sociedade de consumo. Revista de Direito do Consumidor. vol. 107. ano 25. p. 363-384. São Paulo: Ed. RT, Set.- Out., 2016.

SCHNEIDER, Andressa. A concorrência como instrumento: uma análise em função do princípio da defesa do consumidor. Revista de Direito do Consumidor. vol. 105. ano 25. p. 247-270. São Paulo: Ed. RT, Mai.- Jun., 2016.

SILVA, Ana Beatriz B. Mentes consumistas: do consumismo à compulsão por compras. 1 ed. São Paulo: Globo, 2014.

SOLOMON, Michael R. O comportamento do consumidor: Comprando, Possuindo e Sendo. 5 ed. Porto Alegre: Bookman, 2002.

TEDESCHI, Sebastián Ernesto. El waterloo del código civil napoleónico: una mirada crítica a los fundamentos del derecho privado moderno para la construcción de sus nuevos principios 
generales. In: COURTIS, Christian (compilador). Desde otra mirada: texto de teoría crítica del derecho. Buenos Aires: Eudeba, 2001.

TEIXEIRA, Leandro Fernandez. A prática de dumping social como um fundamento de legitimação de punitive damages, em uma perspectiva da Análise Econômica do Direito. 2012. 236 f. Dissertação (Mestrado em Relações Sociais e Novos Direitos). Faculdade de Direito - Universidade Federal da Bahia, 2012.

TRT do Pará multa Santander em R 123 mil por terceirização ilícita. Contraf CUT. maio 2014. Disponível em: <http://www.contrafcut.org.br/noticias/trt-do-para-multa-santander-emr-123-mil-por-terceirizacao-ilicita-8362>. Acesso em 20 jul. 2018.

VERBICARO, Dennis. Consumo e cidadania: identificando os espaços políticos de atuação qualificada do consumidor. Rio de Janeiro: Lumen Juris, 2017. 